\title{
Studi Mengenai Pengaruh Faktor Air-Semen dan Nilai Slump Beton Segar terhadap Permeabilitas Beton
}

\author{
CHANDRA BUDHI RIZKY, PRIYANTO SAELAN
}

Jurusan Teknik Sipil Institut Teknologi Nasional Bandung

Email: chabudh@gmail.com

\begin{abstract}
ABSTRAK
Permeabilitas beton memiliki peran penting dalam mempertahankan umur suatu struktur bangunan, serta dipengaruhi oleh faktor air-semen, dan porositas beton. Dari suatu nilai faktor air-semen yang sama maka dapat dibuat campuran beton dengan nilai slump yang berbeda. Nilai slump yang berbeda membutuhkan jumlah air yang berbeda hal ini diduga akan mengakibat nilai koefiesien permeabilitas yang lebih tinggi. Penelitian ini dilakukan dengan membuat campuran beton menggunakan cara Dreux Gorrise - ITENAS, untuk faktor granular $[G]$ 0,55; faktor air-semen 0,4; 0,5; dan 0,6; serta slump rencana 30-60 $\mathrm{mm}$ dan 60-180 $\mathrm{mm}$. Hasil penelitian ini menunjukan grafik hubungan antara faktor air-semen dan nilai slump dengan nilai koefisien permeabilitas. Hasil dari grafik menunjukan faktor air-semen 0,5 dengan nilai slump 30-60 mm nilai koefisien permeabilitasnya adalah 5,790 × $10^{9} \mathrm{~m} / \mathrm{dtk}$. Sedangkan untuk faktor air-semen 0,5 dengan nilai slump 60-180 mm nilai koefisien permeabilitasnya adalah $7,674 \times 10^{-9} \mathrm{~m} / \mathrm{dtk}$.
\end{abstract}

Kata kunci: permeabilitas beton, porositas beton, nilai slump, faktor air-semen

\begin{abstract}
Permeability of concrete has an important role in maintaining the life of a building structure, also influenced by a water-cement ratio and porosity of the concrete. From a value of the same water-cement ratio, concrete mixtures can be made with different slump values. Different slump values require different amounts of water, this is thought to result in higher permeability coefficient values. This research was carried out by making a concrete mixture using the Dreux Gorrise ITENAS method, for granular factors $[G] 0.55$, water-cement ratio $0.4,0.5$, and 0.6 , and slump plans $30-60 \mathrm{~mm}$ and $60-180 \mathrm{~mm}$. The results of this study show a graph of the relationship between the water-cement ratio and slump value with the permeability coefficient value. The results of the graph show a water-cement factor of 0.5 with a slump value of $30-60 \mathrm{~mm}$ the value of the permeability coefficient is $5.790 \times 10^{-9} \mathrm{~m} / \mathrm{sec}$. While for the water-cement factor 0.5 with a slump value of $60-180 \mathrm{~mm}$ the value of the permeability coefficient is $7.674 \times 10$ ${ }^{9} \mathrm{~m} / \mathrm{sec}$.
\end{abstract}

Keywords: permeability of concrete, porosity of concrete, slump value, watercement ratio 


\section{PENDAHULUAN}

Permeabilitas beton dapat juga diartikan kemampuan bertahan dalam segala kondisi, cuaca, reaksi kimia, dan pengikisan. Permebilitas beton terjadi dalam dua cara yaitu terjebaknya gelembung udara akibat pemadatan beton yang belum sempurna dan rongga yang terbentuk akibat air dalam campuran beton yang menguap pada saat pelaksanaan pekerjaan beton. Faktor yang mempengaruhi permeabilitas beton diantaranya: faktor air-semen dan porositas beton. Semakin tinggi faktor air-semen semakin tinggi permeabilitas beton. Demikian pula dengan porositas beton, semakin tinggi kadar pori beton semakin tinggi permeabilitasnya. . Semakin tinggi nilai s/ump semakin tinggi air yang ditambahkan. Semakin banyak air yang ditambahkan maka beton akan memiliki pori yang makin besar saat beton mengeras disebabkan air yang menguap semakin banyak. Maka semakin tinggi nilai s/ump diduga samakin tinggi permeabilitas.

\section{TINJAUAN PUSTAKA}

\subsection{Permeabilitas Beton}

Permeabilitas beton adalah kemampuan beton untuk dilalui oleh air. Permeabilitas beton terjadi dalam dua cara yaitu terjebaknya gelembung udara akibat pemadatan beton yang belum sempurna dan rongga yang terbentuk akibat air dalam campuran beton yang menguap pada saat pelaksanaan pekerjaan beton. Akibat adanya rongga dan udara pada beton keras maka beton tidak kedap terhadap air, beton yang tidak kedap air mengakibatkan tulangan pada beton akan korosi dan berkurangnya volume air karena air memasuki rongga beton.

Perhitungan permeabilitas menggunakan Hukum Darcy. Hal ini dinyatakan dengan menggunakan Persamaan 1.

$$
K=\frac{\rho g Q L}{P A}
$$

$$
\begin{aligned}
& \text { halmana: } \\
& \begin{aligned}
& K \quad=\text { koefisien permeabilitas }[\mathrm{m} / \mathrm{dtk}] \\
& \rho=\text { massa jenis air }\left[\mathrm{kg} / \mathrm{m}^{3}\right], \\
& g=\text { percepatan gravitasi }\left[\mathrm{m} / \mathrm{dtk}^{2}\right], \\
& Q=\text { debit aliran air }\left[\mathrm{m}^{3} / \mathrm{dtk}\right] \\
& L=\text { panjang atau tinggi sampel }[\mathrm{m}], \\
& P=\text { tekanan air }\left[\mathrm{kg} / \mathrm{m}^{2}\right], \\
& A=\text { luas penampang sampel }\left[\mathrm{m}^{2}\right] .
\end{aligned}
\end{aligned}
$$

\subsection{Faktor-faktor yang Mempengaruhi Permeabilitas Beton}

Permeabilitas beton dipengaruhi oleh beberapa faktor.

\subsubsection{Faktor Air-Semen}

Dalam pencampuran beton, air secara tidak langsung bertanggungjawab pada nilai koefisien permeabilitas. Hal ini ditunjukan dalam Gambar 1. 


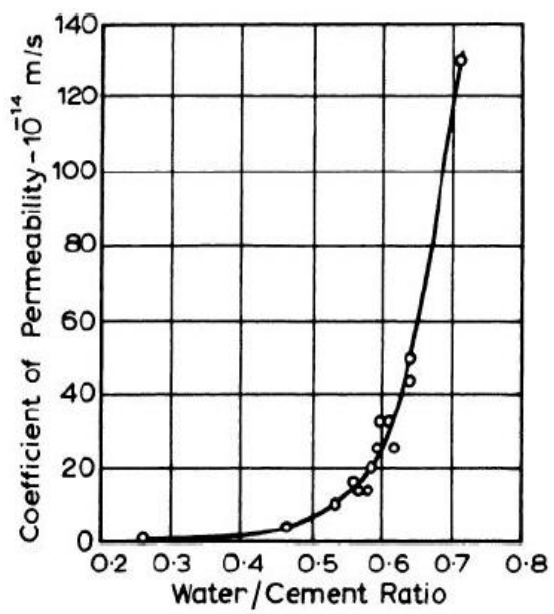

\section{Gambar 1. Hubungan antara permeabilitas pasta semen dan faktor air-semen (Sumber: Neville, A.M., 1963)}

Hasil penelitian pada Gambar 1 dapat dijelaskan berikut ini. Jika faktor air-semen semakin kecil maka jumlah air yang digunakan semakin kecil. Apabila jumlah air yang digunakan semakin kecil maka rongga yang terjadi pada beton keras akan semakin kecil. Jika rongga yang terjadi semakin kecil maka jumlah air yang melewati beton keras semakin sedikit sehingga nilai koefisien permeabilitas beton semakin kecil.

\subsubsection{Porositas Beton}

Dalam beton keras, permeabilitas dipengaruhi oleh ukuran, bentuk, distribusi gradasi, dan kontinuitas dari pori-pori. Karena adanya perbedaan ukuran pasta semen dengan agregat kasar maka permeabilitas yang terjadi akan berbeda. Hal ini disebabkan oleh porositas kapiler. Semakin besar porositas kapiler semakin tinggi nilai koefisien permeabilitas. Hal ini ditunjukan dalam Gambar 2.

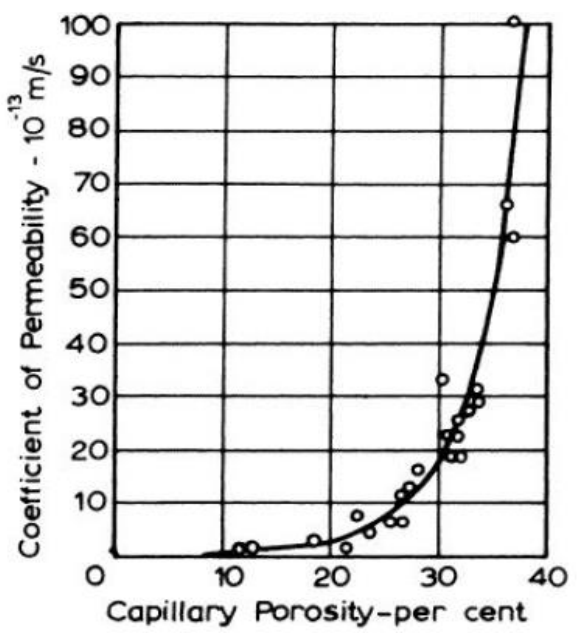

Gambar 2. Hubungan antara permeabilitas dan porositas kapiler (Sumber: Neville, A.M., 1963)

\subsubsection{Nilai Slump}

Faktor-faktor yang mempengaruhi nilai slump dapat dilihat pada Tabel $\mathbf{1}$. 
Tabel 1. Perkiraan Kadar Air Bebas $\left[\mathrm{kg} / \mathrm{m}^{3}\right.$ ] yang Dibutuhkan untuk Beberapa Tingkat Kemudahan Pengerjaan Adukan Beton

\begin{tabular}{cccccc}
\hline \multirow{2}{*}{$\begin{array}{c}\text { Ukuran Besar Butir Agregat } \\
\text { Maksimum [mm] }\end{array}$} & \multirow{3}{*}{ Jenis Agregat } & \multicolumn{4}{c}{ Slump [mm] } \\
\cline { 3 - 6 } & & $\mathbf{0 - 1 0}$ & $\mathbf{1 0 - 3 0}$ & $\mathbf{3 0 - 6 0}$ & $\mathbf{6 0 - 1 8 0}$ \\
\hline \multirow{2}{*}{10} & Batu tak dipecahkan & 150 & 180 & 205 & 225 \\
& Batu pecah & 180 & 205 & 230 & 250 \\
\hline \multirow{2}{*}{20} & Batu tak dipecahkan & 135 & 160 & 180 & 195 \\
& Batu pecah & 170 & 190 & 210 & 225 \\
\hline \multirow{2}{*}{40} & Batu tak dipecahkan & 115 & 140 & 160 & 175 \\
& Batu pecah & 155 & 175 & 190 & 205 \\
\hline
\end{tabular}

Catatan: Koreksi suhu udara (untuk suhu di atas $25{ }^{\circ} \mathrm{C}$, setiap kenaikan $5{ }^{\circ} \mathrm{C}$ harus ditambah air 5 liter per $\mathrm{m}^{2}$ adukan beton)

(Sumber: Badan Standardisasi Nasional, 2000)

Dari Tabel 1 dapat diketahui bahwa faktor yang mempengaruhi nilai s/ump adalah jumlah air, ukuran butir agregat dan tidak dipengaruhi oleh faktor air-semen. Semakin tinggi nilai slump maka semakin tinggi pula jumlah air yang diperlukan. Apabila jumlah air yang digunakan semakin tinggi maka diduga akan membuat rongga udara pada beton keras semakin besar, dan hal ini diduga akan menyebabkan nilai koefisien permeabilitas semakin besar.

Dari suatu nilai faktor air-semen yang sama maka dapat dibuat campuran beton dengan nilai slump yang berbeda. Nilai slump yang berbeda membutuhkan jumlah air yang berbeda. Campuran dengan nilai s/ump yang tinggi membutuhkan jumlah air yang lebih banyak sehingga diduga akan mengakibat nilai koefiesien permeabilitas yang lebih tinggi. Dengan demikian maka permeabilitas beton tidak hanya dipengaruhi oleh faktor air-semen, kepadatan atau berat jenis agregat, tetapi juga oleh nilai slump.

\section{METODOLOGI PENELITIAN}

\subsection{Prosedur Penelitian}

Prosedur penelitian mengenai studi pengaruh faktor air-semen dan nilai slump beton segar terhadap permeabilitas beton dilakukan dengan tahapan-tahapan yang tertera pada Gambar 3.

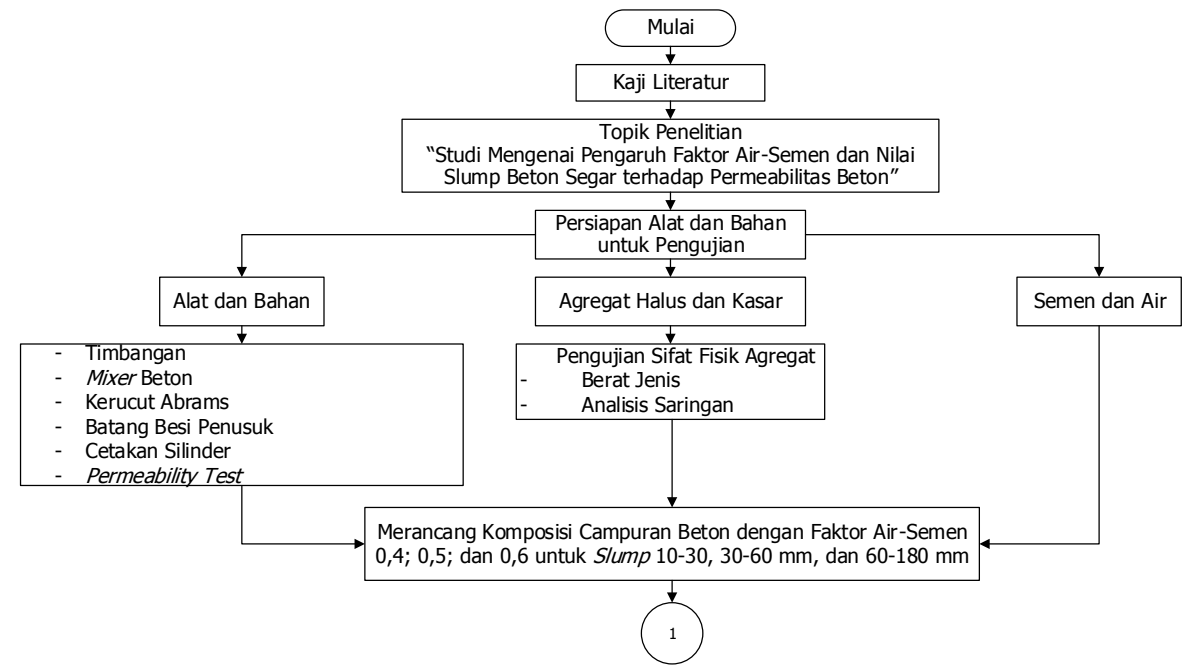

Gambar 3. Bagan alir metode penelitian 


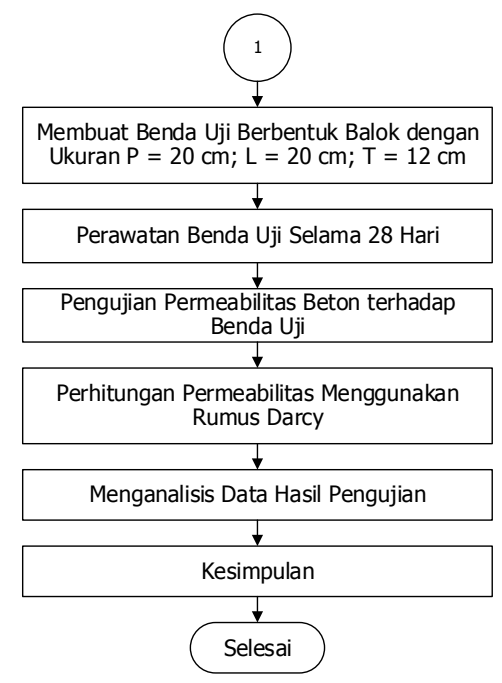

Gambar 3. Bagan alir prosedur penelitian lanjutan

\subsection{Data Penelitian}

Data Penelitian yang digunakan dalam penelitian ini meliputi data primer. Data primer terdiri dari data material yang digunakan, diperoleh melalui pengujian dan pemeriksaan material, meliputi berat jenis agregat halus dan kasar, absorpsi, dan modulus kehalusan, yang diperlihatkan pada Tabel 2. Data komposisi campuran beton untuk membuat benda uji balok dengan ukuran panjang $20 \mathrm{~cm}$, lebar $20 \mathrm{~cm}$, dan tinggi $12 \mathrm{~cm}$ sebanyak 12 buah, yang diperlihatkan pada Tabel $\mathbf{3}$ dan Tabel 4, serta Gambar 4. Data hasil perhitungan permeabilitas beton berdasarkan pengujian permeabilitas beton.

Tabel 2. Hasil Pengujian Fisik Material yang Digunakan

\begin{tabular}{lccc}
\multicolumn{1}{c}{ Parameter } & Semen & Agregat Kasar & Agregat Halus \\
\hline Berat Jenis Kondisi SSD $\left[\mathrm{kg} / \mathrm{m}^{3}\right]$ & 3,15 & 2,65 & 2,55 \\
\hline Berat Jenis Kondisi Kering $\left[\mathrm{kg} / \mathrm{m}^{3}\right]$ & - & 2,565 & 2,408 \\
\hline Absorpsi [\%] & - & 3,665 & 5,932 \\
\hline Modulus Kehalusan [FM] & - & - & 2,773 \\
\hline
\end{tabular}

Tabel 3. Komposisi Campuran Beton untuk $1 \mathbf{~ m}^{3}$

\begin{tabular}{ccccccc}
\hline & \multicolumn{2}{c}{ Faktor Air-Semen 0,4 } & \multicolumn{2}{c}{ Faktor Air-Semen 0,5 } & \multicolumn{2}{c}{ Faktor Air-Semen 0,6 } \\
Bahan & \multicolumn{2}{c}{ Nilai Slump $[\mathbf{m m}]$} & Nilai Slump [mm] & \multicolumn{2}{c}{ Nilai S/ump [mm] } \\
& $\mathbf{3 0 - 6 0}$ & $\mathbf{6 0 - 1 8 0}$ & $\mathbf{3 0 - 6 0}$ & $\mathbf{6 0 - 1 8 0}$ & $\mathbf{3 0 - 6 0}$ & $\mathbf{6 0 - 1 8 0}$ \\
\hline Semen [kg] & 525 & 590 & 420 & 472 & 350 & 393,333 \\
\hline Pasir [kg] & 935 & 935 & 779,167 & 935 & 779,167 & 779,167 \\
\hline Batu Pecah [kg] & 627,167 & 503,584 & 877,444 & 602,854 & 936 & 830,978 \\
\hline Air [kg] & 210 & 236 & 210 & 236 & 210 & 236 \\
\hline
\end{tabular}

Tabel 4. Benda Uji Permeabilitas Beton

\begin{tabular}{|c|c|c|c|c|}
\hline Faktor Air-Semen & \multicolumn{2}{|c|}{ Nilai Slump [mm] } & Bentuk Benda Uji & $\begin{array}{l}\text { Jumlah } \\
\text { Benda Uji }\end{array}$ \\
\hline 0,4 & $30-60$ & $60-180$ & $20 \mathrm{~cm} \times 20 \mathrm{~cm} \times 12 \mathrm{~cm}$ & 4 \\
\hline 0,5 & $30-60$ & $60-180$ & $20 \mathrm{~cm} \times 20 \mathrm{~cm} \times 12 \mathrm{~cm}$ & 4 \\
\hline 0,6 & $30-60$ & $60-180$ & $20 \mathrm{~cm} \times 20 \mathrm{~cm} \times 12 \mathrm{~cm}$ & 4 \\
\hline \multicolumn{4}{|c|}{ Jumlah Total Benda Uji } & 12 \\
\hline
\end{tabular}




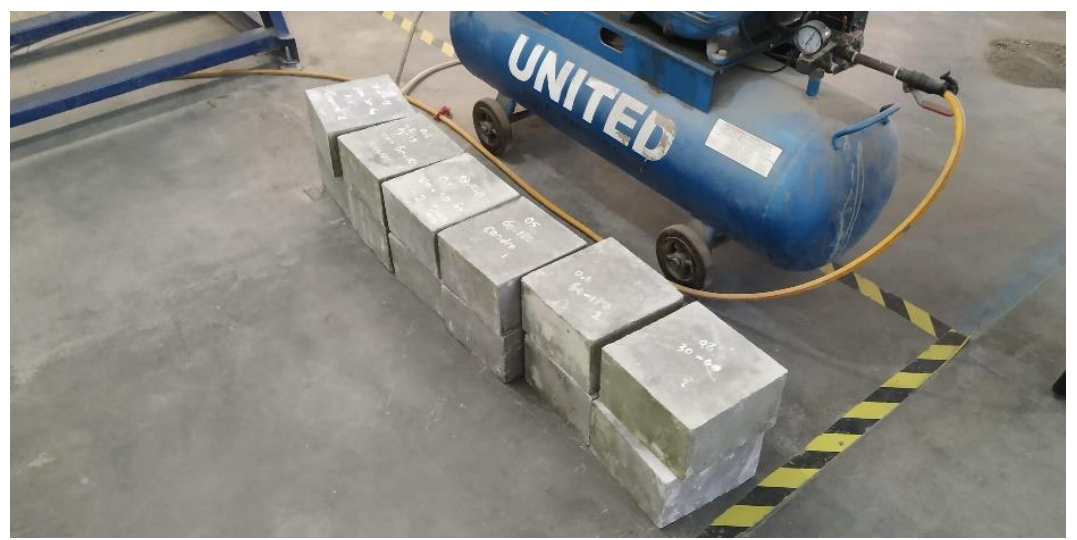

Gambar 4. Benda uji

\subsection{Variabel Penelitian}

Variabel penelitian ini terdiri dari:

1. Faktor air-semen 0,$4 ; 0,5$; dan 0,6 .

2. Nilai slump 30-60 mm dan $60-180 \mathrm{~mm}$.

3. Massa jenis air $1.000 \mathrm{~kg} / \mathrm{m}^{3}$.

4. Tekanan air $5 \mathrm{~kg} / \mathrm{cm}^{2}$.

5. Percepatan gravitasi $9,81 \mathrm{~m} / \mathrm{dtk}^{2}$.

\section{HASIL PENELITIAN DAN PEMBAHASAN}

\subsection{Hasil Penelitian}

Hasil pengujian permeabilitas beton ditunjukan pada Tabel 5.

Tabel 5. Hasil Pengujian Permeabilitas Beton

\begin{tabular}{cccccc}
\hline $\begin{array}{c}\text { Faktor } \\
\text { Air- } \\
\text { Semen }\end{array}$ & $\begin{array}{c}\text { Nilai Slump } \\
\text { Aktual } \\
{[\mathbf{m m}]}\end{array}$ & $\begin{array}{c}\text { Koef. } \\
\text { Permeabilitas } \\
\mathbf{\times} \mathbf{1 0}^{-9}[\mathbf{m} / \mathbf{d t k}]\end{array}$ & $\begin{array}{c}\text { Kedalaman } \\
\text { Penetrasi } \\
{[\mathbf{c m}]}\end{array}$ & $\begin{array}{c}\text { Syarat } \\
\text { DIN 1045 }\end{array}$ & Keterangan \\
\hline \multirow{2}{*}{0,4} & 60 & 5,790 & 2,75 & $<5 \mathrm{~cm}$ & memenuhi \\
\cline { 2 - 6 } & 80 & 5,790 & 2,7 & $<5 \mathrm{~cm}$ & memenuhi \\
\hline \multirow{2}{*}{0,5} & 40 & 5,790 & 2,2 & $<5 \mathrm{~cm}$ & memenuhi \\
\hline \multirow{2}{*}{0,6} & 100 & 7,674 & 5,35 & $<5 \mathrm{~cm}$ & tidak memenuhi \\
\cline { 2 - 6 } & 50 & 7,674 & 6,1 & $<5 \mathrm{~cm}$ & tidak memenuhi \\
\hline
\end{tabular}

Pada Gambar 5 dan Gambar 6 menunjukan hasil uji permeabilitas beton dalam bentuk grafik. 


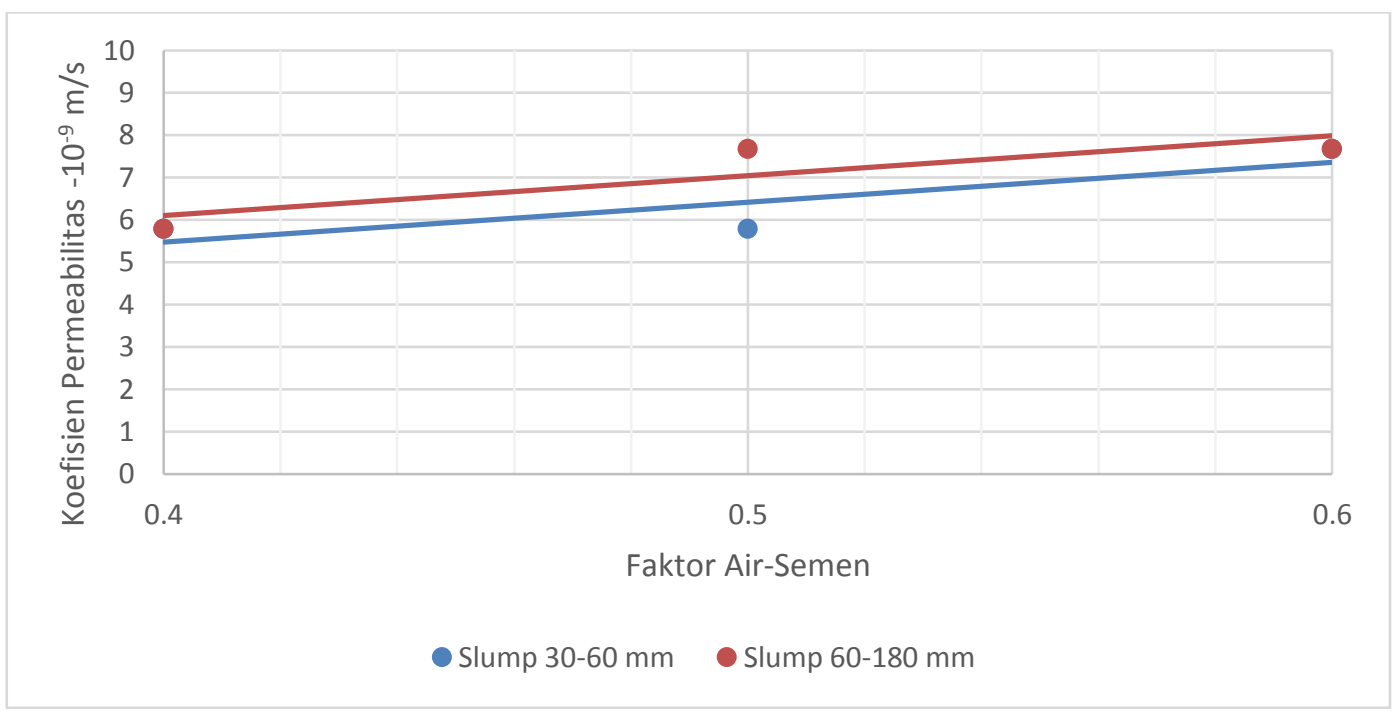

Gambar 5. Hubungan antara permeabilitas dengan faktor air-semen dan nilai s/ump

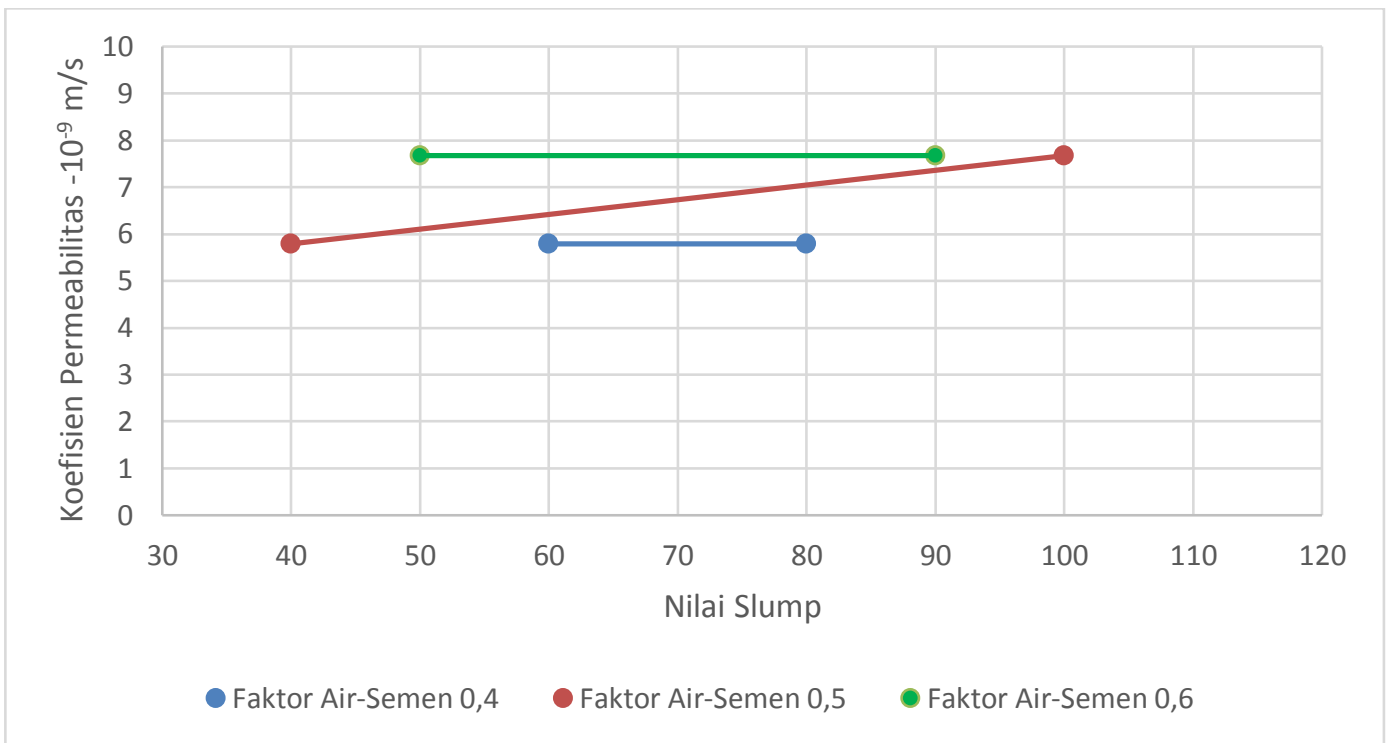

Gambar 6. Hubungan antara permeabilitas dengan nilai slump dan faktor-air semen

\subsection{Pembahasan}

Hasil uji permeabilitas rata-rata pada faktor air-semen 0,4 dengan nilai s/ump 30-60 mm serta 60-180 mm nilai koefisien permeabilitasnya adalah 5,337 x 10-9 m/dtk. Untuk faktor air semen 0,5 dengan nilai s/ump 30-60 mm koefisien permeabilitasnya adalah 5,337 x 10-9 $\mathrm{m} / \mathrm{dtk}$. Untuk nilai s/ump 60-180 mm koefisien permeabilitasnya adalah $6,052 \times 10^{-9} \mathrm{~m} / \mathrm{dtk}$. Sedangkan untuk faktor air semen 0,6 dengan nilai s/ump 30-60 mm serta 60-180 mm nilai koefisien permeabilitasnya adalah $6,052 \times 10^{-9} \mathrm{~m} / \mathrm{dtk}$.

Berdasarkan hasil uji di atas nilai koefisien permeabilitas memiliki nilai yang lebih besar dibandingkan dengan pengujian pada Gambar 1. Hal tersebut karena adanya perbedaan pada benda yang diujikan. Benda uji beton memiliki nilai porositas yang tinggi. Dengan demikian dugaan nilai s/ump dapat mempengaruhi nilai koefisien permeabilitas adalah benar. Sehingga semakin tinggi nilai slump semakin tinggi nilai koefisien permeabilitas. 


\section{KESIMPULAN DAN SARAN}

\subsection{Kesimpulan}

Berdasarkan hasil penelitian dan pembahasan dapat disimpulkan sebagai berikut:

a. Perancangan campuran beton menggunakan faktor air-semen 0,$4 ; 0,5$ dan 0,6 dengan nilai slump 30-60 mm dan 60-180 mm menghasilkan nilai koefisien permeabilitas lebih tinggi dibandingkan dengan hasil penelitian pada Gambar 1.

b. Dilihat dari hasil kedalaman penetrasi, untuk faktor air-semen 0,5 dengan nilai s/ump 60$180 \mathrm{~mm}$ tidak dapat digunakan pada struktur yang berinteraksi langsung dengan air.

c. Dilihat dari hasil kedalaman penetrasi, untuk faktor air-semen 0,6 dengan nilai s/ump 30-60 mm dan 60-180 mm tidak dapat digunakan pada struktur yang berinteraksi langsung dengan air.

d. Dengan rentang nilai koefisien permeabilitas $1 \times 10^{-9} \mathrm{~m} / \mathrm{dtk}$ maka hasil yang didapatkan termasuk beton dengan permeabilitas rendah.

\subsection{Saran}

Berdasarkan hasil penelitian dan pembahasan dapat disimpulkan sebagai berikut:

a. Hasil dari studi ini perlu dikaji lebih lanjut dikarenakan nilai koefisien permeabilitas yang dihasilkan hanya memiliki perbedaan yang terjadi pada faktor air-semen 0,5.

b. Alat pengujian yang digunakan memiliki ketelitian yang kurang dikarenakan pembacaan alat belum menggunakan sistem komputer sehingga faktor kesalahan pembacaan hasil lebih besar sehingga diperlukannya penelitian ulang dengan alat pengujian yang berbeda agar menghasilkan nilai koefisien permeabilitas yang lebih tepat.

\section{DAFTAR RUJUKAN}

Badan Standardisasi Nasional. (2000). SNI 03-2834-2000 tentang Tata Cara Pembuatan Rencana Campuran Beton Normal. Jakarta: Badan Standardisasi Nasional.

Neville, A. M. (1963). Properties of Concrete $4^{\text {th }}$ Edition. Harlow: Pearson Education. 